\title{
A process-based perspective on strategic planning: the role of alternative generation and information integration
}

\author{
Philip Meissner
}

Received: 19 August 2013/Accepted: 5 December 2013/Published online: 13 May 2014

(C) The Author(s) 2014. This article is published with open access at Springerlink.com

\begin{abstract}
To help bridge the gap between the emergent and rational school of strategy formation, I analyze the role of alternative generation and information integration as two process-based characteristics of the strategy process in the relationship between strategic planning and decision quality. Based on a survey of 155 top executives from German small and medium-sized companies, I show that the degree to which multiple alternatives are developed and information is integrated in the planning process mediates a large proportion of the relationship between strategic planning and decision quality. This suggests that a closer analysis of process characteristics in the analysis of strategic planning may help mitigate the divergent results in strategic planning research.
\end{abstract}

Keywords Strategic planning - Alternative generation · Information integration · Decision quality - Strategy process · Planned emergence . Process-based characteristics - Strategy process outcome

JEL Classification $\mathrm{M} 10 \cdot \mathrm{L} 21 \cdot \mathrm{L} 22$

\section{Introduction}

Strategic planning has remained a dominant management technique in corporate practice (Grant 2003). Rigby and Bilodeau (2007), for example, show that top managers continue to rate strategic planning as one of the most influential tools for

Responsible editor: Thomas Hutzschenreuter (Management).

P. Meissner $(\bowtie)$

Chair of Strategic and International Management, Philipps-University Marburg, Universitätsstr. 24,

35037 Marburg, Germany

e-mail: philip.meissner@uni-marburg.de 
strategic management. This trend is supported by an increased introduction of Chief Strategy Officers at board level, who are responsible for strategic planning (Breene et al. 2007).

Despite this importance in corporate practice, research results on the effect of strategic planning in organizations have been mixed (e.g., Ackelsberg and Arlow 1985; Andersen 2000; Capon and Palij 1994; Delmar and Shane 2003; Pearce et al. 1987; Shrader et al. 1984). These divergent results have inspired a debate on the effectiveness of strategic planning in general and on the underlying process and its characteristics in particular. Most prominently this has been reflected in the ongoing discussion between the emergent and rational school of strategy formation (Ansoff 1991; Mintzberg 1991, 1994). More recent research, however, argues that only a combination of both perspectives can provide a more accurate and prescriptive representation of strategic planning in organizations (Brown and Eisenhardt 1997; Grant 2003).

This new perspective called 'planned emergence' constitutes a shift from the traditional perception of strategic planning as a resource deployment process towards viewing 'strategy as aspirations and performance goals' (Grant 2003). In his seminal analysis of major oil companies, Grant (2003) found that these new planning processes in organizations are typically characterized by shorter planning horizons, greater flexibility, and an increased emphasis on performance targets that primarily aim at controlling and coordinating the different parts of the business. This research also suggests that the precise characteristics of the planning process and its design play an important role in determining if strategic planning can ultimately contribute towards coordinating strategic decision making and driving strategy process outcomes such as organizational performance or decision quality (Andersen 2000; Grant 2003; Hutzschenreuter and Kleindienst 2006). In this context, particularly studying the effect of strategic planning processes on decision quality rather than performance has provided promising results as decision quality can provide a more direct and proximate outcome measure of the strategy process (Amason 1996; Dean and Sharfman 1996; Forbes 2007; Hart and Banbury 1994; Keren and de Bruin 2003).

Strategic planning as well as strategy process research indicates that companies, which structure their planning processes according to the planned emergence perspective, seem to also integrate two particular process characteristics to create effective strategic planning processes. Namely these processes integrate the development of different alternatives and the integration of divergent information to use strategic planning as a tool for coordination in the organization (AtuaheneGima and Li 2004; Grant 2003; Miller et al. 1998). In this paper, I analyze the role of these process characteristics in the strategic planning process based on survey data from 155 executives in German small and medium-sized companies. Specifically, I show that both multiple alternative generation and information integration are crucial mediators in the strategic planning decision quality link.

The results reported in this paper contribute to the discussion on the effects of strategic planning in the strategy process by extending the analysis on the planned emergence perspective of strategic planning. They suggest that strategic planning may be particularly beneficial in organizations if certain process characteristics are 
met. Thus, this paper contributes to research in the domain by opening the discussion on strategic planning for a more process-based analysis, which can help improve our understanding on the precise mechanisms affecting the strategy process in organizations. It adds to the strategic planning literature by suggesting that the specific design of the strategic planning process can change or alter its effect on the outcome of the strategy process.

\section{Background and hypotheses}

Strategic planning has been traditionally seen as a set of standardized planning guidelines or written plans that follow a normative approach (Boyd and ReuningElliott 1998; Miller and Cardinal 1994). It results in the formulation of one optimal strategy (Armstrong 1982). This view defines strategic planning as a formalized and systematic approach to strategy development (Ansoff 1991, 1965). Early empirical research in the domain has largely focused on analyzing the effect of strategic planning on the strategic decision making process in general and its impact on firm performance in particular (Grant 2003). However, this research has been largely inconclusive. Some empirical studies found support for a positive relationship between strategic planning and performance (for an overview see Andersen 2000). However, others have found evidence for a negative planning performance link (e.g., Capon and Palij 1994; Pearce et al. 1987; Shrader et al. 1984) or even no relationship at all (Ackelsberg and Arlow 1985).

Another line of research analyzing the strategy process of organizations has followed a more process-oriented approach, which studies the decision quality obtained in strategic planning rather than performance as an outcome measure of the process (Amason 1996; Keren and de Bruin 2003). This research is based on the assumption that the strategy process itself can be a valuable capability, which may ultimately positively influence performance (Hart and Banbury 1994; Hart 1992). In fact, decision quality itself is a crucial outcome of strategic planning that also may be more directly affected by the process as well as the involved actors (Dean and Sharfman 1996; Hitt and Tyler 1991). Early research following this process-based perspective has provided promising results supporting this argument. It shows that decision quality may provide a more proximate outcome measure of the strategy process, which can be less biased from environmental developments that cannot be influenced by the organization itself (Forbes 2007).

Still, neither perspective studying the planning process focusing on performance as its ultimate outcome on the one hand nor the underlying process and its resulting decision quality on the other hand have yet yielded a clear picture of the effect of strategic planning in organizations. This lack of a clear relationship between strategic planning and its potential benefits in the strategy process has inspired an ongoing debate on the characteristics of the planning process itself. In contrast to Ansoff's perspective (Ansoff 1991) that effective planning follows a standardized process, Mintzberg (1994) has argued that successful strategies can never be planned in a formalized way. Rather, he posits that successful strategies emerge in an informal process that involves creativity, intuition and learning. In this context, 
unstructured strategic thinking becomes more important than formal strategic planning (Mintzberg 1991, 1994). However, both lines of research have often been criticized as strategic planning processes have changed significantly over the last decades to account for more complex and dynamic environments. Thus, many critics argue that most assumptions of the traditional models proposed by Mintzberg and Ansoff do not closely reflect real world planning processes that are conducted in organizations today (Andersen 2000; Brown and Eisenhardt 1997; Grant 2003).

Still, more recent research on strategic planning has continued to study the process-based characteristics of strategic planning. However, rather than continuing the debate on strategic planning in an either/or manner (Ansoff 1991; Mintzberg 1991), an integrative approach, which includes both perspectives in the analysis of the planning process in organizations, has emerged (Grant 2003). This line of research implies that the process-related characteristics of strategic planning, which describe the precise elements of how the analyses are conducted, rather than the schematic analyses of the process or the design school can help determine the effectiveness of strategic planning (Brews and Purohit 2007; Wiltbank et al. 2006). This suggests that rather than asking if corporations should conduct strategic planning or not, research in the domain should focus on answering the question of how this planning process should be designed to obtain the desired outcomes (Andersen 2000; Grant 2003).

This new perspective called 'planned emergence' constitutes a shift from the traditional perception of strategic planning as a resource deployment process towards seeing planning 'as aspirations and performance goals' and aims at coordinating strategic decision making and driving performance in organizations by controlling and coordinating its different parts (Grant 2003). In general, this perspective to strategic planning can be characterized by two guiding principles: autonomous and flexible decision making in the organization combined with guidelines and performance expectations set by corporate management (Grant 2003), both of which have been supported by related research in the domain emphasizing their benefits for strategic management (Brown and Eisenhardt 1997; Eisenhardt and Sull 2001).

On a more detailed process-related level, companies that structure their planning processes according to the planned emergence perspective also seem to integrate two characteristics to effectively utilize their strategic planning as a tool for coordination in the organization. First, they integrate different strategic alternatives based on scenarios for an interactive strategy formulation (Grant 2003; Schoemaker 1993). Second, they integrate different perspectives in the organization by extensively discussing their strategic plans and integrating divisional as well as corporate functions to coordinate decentralized decision making (Grant 2003). The goal of this process is to make the respective assumptions of decision makers explicit and share perceptions and experiences based on methods such as mental mapping (Hodgkinson et al. 1999). This observation on the effectiveness of multiple alternative generation and information integration in the strategic planning processes is supported by research in the strategy process domain, which suggests that both characteristics of the planning process may improve strategy process outcomes (Atuahene-Gima and Li 2004; Dean and Sharfman 1996; Miller 2008). 
I argue that a more specific analysis of these two process-based characteristics and their respective role in the strategic planning process can extent the discussion on the planned emergence perspective of strategic planning by improving our understanding on the precise mechanisms affecting the strategy process in organizations. Specifically, I claim that both characteristics will play a crucial role in the strategic planning decision quality link following a process-based perspective (Amason 1996; Forbes 2007; Keren and de Bruin 2003). I posit that multiple alternative generation and information integration, respectively, will mediate this relationship thus showing that is not important if but rather how strategic planning is conducted in organizations to obtain better results in the strategy process.

\subsection{Multiple alternative generation as a mediator in the relationship} between strategic planning and decision quality

Alternative generation describes the degree to which multiple courses of action and decision criteria are evaluated in the process to determine a strategic choice (Fredrickson and Mitchell 1984; Miller et al. 1998). Companies such as Shell, which have been found to follow a planning process rooted in the planned emergence perspective integrate multiple alternative courses of action based on different scenarios (Grant 2003). By surfacing decision maker's underlying assumptions and expanding their perception for different potential future developments, such processes have been shown to effectively reduce biased judgment and increase decision quality (Bradfield 2008; Meissner and Wulf 2013; Schoemaker 1993).

Also prior strategy process research suggests that considering multiple courses of action may positively contribute to different process outcomes based on its positive effect on decision making (Fredrickson 1984; Fredrickson and Mitchell 1984). This effect can be based on the positive cognitive conflict such an approach creates among the management team. Studies that have analyzed determinants of decision quality suggest that it is positively influenced by cognitive conflict based on divergent perspectives (Amason 1996).

A broad development of alternatives prior to selecting the final strategy is likely to grow cognitive diversity in the decision making team (Olson et al. 2007). It can be used to discuss divergent opinions as it enables the team to express new ideas by presenting additional strategy alternatives without directly criticizing the points of view of others. It can thus contribute to consensus building in the process (Dooley and Fryxell 1999). In addition, decision makers are less limited in their way of thinking in terms of being anchored to one initially presented optimal strategy (Schwenk 1988).

The degree to which different alternatives are generated in the strategic planning process thus seems to play a crucial role in determining the effectiveness of the strategy planning process. Thus, I argue that it is not the sheer application of strategic planning that affects decision quality but rather how this process is conducted. In summary, these arguments suggest that strategic planning may be positively associated with decision quality if and because it increases multiple alternative generation. Thus, I propose that:

Hypothesis 1: Multiple alternative generation mediates the relationship between strategic planning and decision quality. 
2.2 Information integration as a mediator in the relationship between strategic planning and decision quality

The arguments mentioned above show that strategic planning can be beneficial for strategic decisions if multiple strategic alternatives are developed prior to strategic choice. However, also the level of information integration as another process-related dimension of the strategic planning frequently applied in planned emergence processes may crucially determine the overall level of decision quality obtained in the process. Information integration is defined as the degree to which external information and scanning procedures are implemented to gain a wide range of divergent information (Dean and Sharfman 1993; Forbes 2007).

Gaining information from different internal and external groups enables the management team to think of strategic problems in new ways (Bonaccio and Dalal 2006; Schotter 2003). This can increase the level of dissent and discussion in the group, which ultimately improves decision quality compared to teams, in which the level of dispute is low (Schweiger et al. 1989). The integration of information from different sources can thus foster cognitive diversity in the management team and contribute towards more effective strategy process outcomes (Olson et al. 2007).

In addition, an internal information search fosters the integration of employees in the strategic planning process, which can contribute to consensus building in the decision process, a factor that has been positively associated with decision quality (Dooley and Fryxell 1999). Furthermore, the consideration of input from the organization has been found to improve the quality of strategic decisions by increasing commitment to the decision as well as trust (Korsgaard et al. 1995). This communication and knowledge sharing can thus improve strategic decisions and even contribute towards coordinating decentralized decision making in organizations (Grant 2003). A higher integration of information in the strategic planning process is thus likely to positively affect decision quality in organizations.

Combining these arguments, I argue that the degree of information integration may be another important intermediary in the strategic planning decision quality relationship. Thus, strategic planning may also be positively associated with decision quality if and because it increases information integration. This reasoning is reflected in my second hypothesis:

Hypothesis 2: Information integration mediates the relationship between strategic planning and decision quality.

\section{Methods}

\subsection{Sample}

One hundred and fifty five top executives from German small and medium-sized companies (SMEs) participated in this study. The companies that these executives managed had an average of 216 employees (ranging between 6 and 950 with a standard deviation of 227) and were active in different industries, most commonly 
engineering (12\%), retail (7\%), and automotive ( $7 \%$ ). The data were collected in a mail-based survey, which was administered carefully to reduce biases in the process and among participants (Dillman 1991; Dillman et al. 1993). Before the actual survey, the questionnaire was pilot tested with 11 executives and modified based on their comments.

The final questionnaire was sent to the top executives of 3,500 companies by mail. These managers were randomly selected from the Hoppenstedt database that comprises one of the largest databases on SMEs in Germany. One follow-up request was sent to non-respondents (Dillman 1978, 1991). Overall, 370 companies responded to the survey, which translates into a response rate of $10.5 \%$. The questionnaires were then analyzed for missing data and regarding the person, who ultimately answered the respective questions in the organization. As this paper analyses the decision quality of strategic decisions, it was essential to receive feedback directly from the top executives, who can best assess these factors. Thus, 100 of the responses had to be excluded from the analysis as an assistant or staff member rather than the executive completed the survey. Twenty eight further responses were excluded from the analysis to correct for outliers in company size and ensure a high degree of comparability among the firms studied. Additionally, 87 questionnaires had to be excluded due to missing data, yielding a final sample size of 155. This response rate in in line with other board-level studies that analyzed confidential issues such as decision quality or performance (Agle et al. 1999; Cruz et al. 2010; Zellweger et al. 2011).

\subsection{Measures}

\subsubsection{Independent variable}

Strategic planning (eigenvalue $=2.52, \alpha=0.78$ ) was measured based on seven items. Participants were asked to evaluate the degree to which different planning instruments are used in their organizations. These included mission statement, trend analysis, competitor analysis, long-term plans, annual goals, short-term action plans, and ongoing evaluation. These items were each measured on a 5-point Likert scale (Boyd and Reuning-Elliott 1998) and could be evaluated from $1=$ no emphasis to $5=$ very strong emphasis.

\subsubsection{Dependent variables}

Decision quality (eigenvalue $=2.13, \alpha=0.89$ ) was measured based on the threeitem scale by Amason (1996). The executives were asked to think back to an important strategic decision that they had recently made. In a next step, they had to evaluate this decision on a seven-point scale $(1=\mathrm{bad} ; 7=$ excellent $)$ in terms of the overall quality of their decision, the quality of the decision relative to the original intent, and the quality of the decision given its effect on organizational performance (Amason 1996). 


\subsubsection{Mediating variables}

Both mediating variables multiple alternative generation and information integration describe important yet distinct dimensions of the strategy process, which are frequently conducted in a parallel way in the strategic planning process of organizations.

To measure multiple alternative generation (eigenvalue $=1.28, \alpha=0.84$ ), respondents were asked to evaluate their decision making processes in non-routine situations, such as a situation requiring a major strategic decision (Miller et al. 1998). The degree to which multiple alternatives were developed in these decision processes was then evaluated based on two items on a seven-point Likert scale, which ranged from $1=$ not at all to $7=$ to a great extent. One item for example asked respondents: "When confronted with an important, non-routine problem or opportunity, to what extent did your firm develop many alternative responses?" (Miller et al. 1998).

To measure information integration (eigenvalue $=1.54, \alpha=0.80$ ), respondents were asked to report their approach in the same situation evaluated when judging the degree of "multiple alternative generation" (Miller et al. 1998). The information integration in this process was measured based on three items, which also relied on a seven-point Likert scale. These items included for example "the degree to which the firm extensively searched for possible responses" and "the degree to which the firm thoroughly examined multiple explanations for the problem or opportunity?" (Miller et al. 1998).

\subsubsection{Control variables}

Four variables were included as controls in this study. Perceived Uncertainty (eigenvalue $=2.12, \alpha=0.79$ ) was measured based on five items. Respondents were asked to evaluate their perceptions on the intensity of uncertainty in their industry using a seven-point scale (Miller and Dröge 1986). The executives' perception of uncertainty was controlled for as it has been shown to affect the strategy process and its outcome by prior research (Miller 2008). Three additional variables were controlled for. Performance expectation was measured as the logarithm of a three-item scale (eigenvalue $=2.05, \alpha=0.88$ ). Respondents rated the average performance within the last 5 years (Hart and Banbury 1994; Venkatraman and Ramanujam 1987) for example "relative to their plan". This measure was included to control for possible differences in the expectation and subjective evaluation of profitability. Subjective performance scale (eigenvalue $=1.89, \alpha=0.84$ ) was controlled for to account for different performance levels among the organizations in the sample. It was measured on three items following the approach suggested by Hart and Banbury (1994). The last control variable size was measured as the logarithm of the number of employees. It was included as a control variable because large corporations may have additional slack that enables them to engage in more comprehensive planning processes (AtuaheneGima and Li 2004). 


\section{Results}

Descriptive statistics and correlations for all variables used in this analysis are summarized in Table 1. The table exhibits a high correlation of 0.70 between the two mediating variables information integration and multiple alternative generation. This correlation could bias the results of the analysis due to multicollinearity if both variables were analyzed in a combined mediation model. To overcome such concerns, I decided to study the influence of each mediator in separate analyses, which are summarized below. The common method bias as well as the non-response bias were accounted for by the application of Harman's single factor test (Podsakoff et al. 1984) and by comparing answers from late and early responders in the survey (Churchill 1991). Both tests indicated the absence of the respective biases. Furthermore, condition numbers for the variables ranged from 16.89 to 18.26 thus indicating the absence of collinearity (Wang and Zajac 2007).

To test my two hypotheses, I applied the methodology for mediation analyses proposed by Baron and Kenny (1986). This requires the analysis of four different regression models, which I applied for each of the two hypotheses analyzing both multiple alternative generation and information integration. In this case, the first model can be applied in both cases. It analyzes the effect, which may be mediated. This so-called $X-Y$ relation tests the proposed positive association between strategic planning and decision quality. Model 1 showed a positive and significant relationship between the two variables $(b=0.32, p<0.01)$ that supports an underlying positive relationship between strategic planning and decision quality. Based on this initial result, the other six models tested the mediation of multiple alternative generation and information integration in this relationship, respectively.

My first hypothesis, suggesting a mediation of multiple alternative generation in the strategic planning decision quality relationship, was tested in Models 2-4. For this mediation, three conditions have to hold true (Baron and Kenny 1986). First, the independent variable has to be positively associated with the potential mediator (Model 2). Second, the presumed mediator has to positively influence the dependent variable (which is analyzed in Model 3). The final condition states that the previously significant relationship between the independent and the dependent variable has to become insignificant after the mediator has been integrated into the model (Model 4). The results of these analyses are summarized in Table 2.

Models 2-4 showed that all conditions proposed by Baron and Kenny (1986) for a mediation effect of multiple alternative generation in the relationship between strategic planning and decision quality were fulfilled. Model 2 showed that strategic planning had a positive and highly significant effect on multiple alternative generation $(b=0.78, p<0.001)$. Furthermore, the relationship between multiple alternative generation and decision quality was positive and highly significant in Model $3(b=0.21, p<0.001)$. The results of Model 4 also confirmed the third condition for a mediation effect of multiple alternative generation. The model showed that strategic planning was no longer positively associated with decision quality ( $b=0.19$, n.s.) when multiple alternative generation was included. Instead, multiple alternative generation as a mediator had a highly significant and positive effect on decision quality $(b=0.18, p<0.001)$. In addition, the mediation analysis 


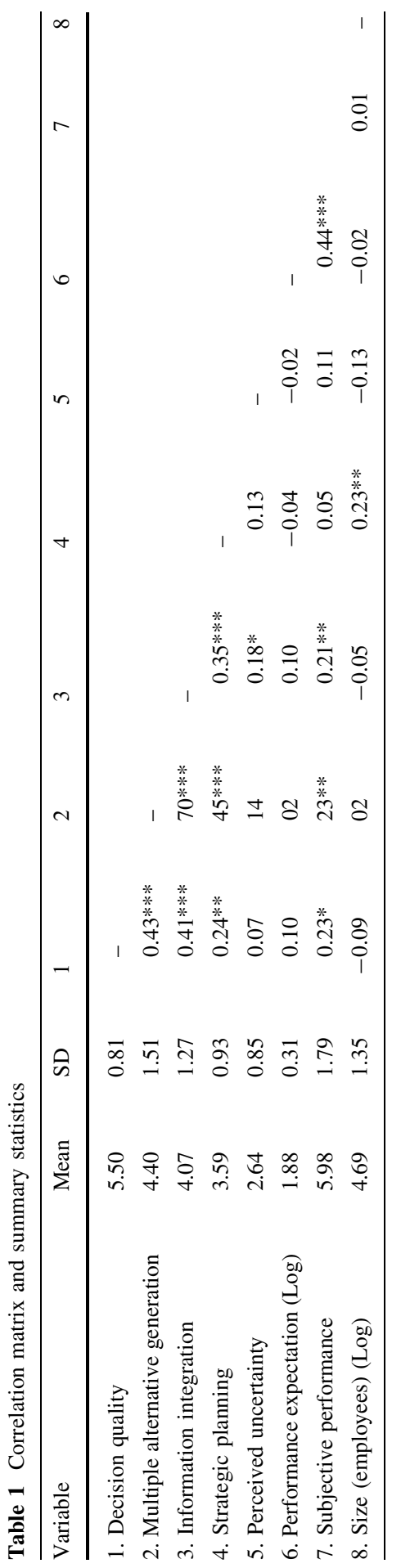


Table 2 Mediation effect of multiple alternative generation, according to Baron and Kenny (1986)

\begin{tabular}{|c|c|c|c|c|}
\hline Variables & $\begin{array}{l}\text { Model } 1 \\
\text { decision } \\
\text { quality }\end{array}$ & $\begin{array}{l}\text { Model } 2 \\
\text { multiple alternative } \\
\text { generation }\end{array}$ & $\begin{array}{l}\text { Model } 3 \\
\text { decision } \\
\text { quality }\end{array}$ & $\begin{array}{l}\text { Model } 4 \\
\text { decision } \\
\text { quality }\end{array}$ \\
\hline \multicolumn{5}{|l|}{ Controls } \\
\hline 1. Perceived uncertainty & -0.00 & 0.17 & -0.02 & -0.03 \\
\hline $\begin{array}{l}\text { 2. Performance } \\
\text { expectation (Log) }\end{array}$ & 0.02 & 0.20 & -0.04 & -0.01 \\
\hline $\begin{array}{l}\text { 3. Subjective } \\
\text { performance }\end{array}$ & $0.11^{*}$ & 0.15 & 0.08 & 0.08 \\
\hline $\begin{array}{l}\text { 4. Size (employees) } \\
\text { (Log) }\end{array}$ & $-0.10^{*}$ & -0.14 & -0.05 & -0.08 \\
\hline \multicolumn{5}{|l|}{ Main effects } \\
\hline Strategic planning & $0.32 * *$ & $0.78^{* * *}$ & - & 0.19 \\
\hline $\begin{array}{l}\text { Multiple alternative } \\
\text { generation }\end{array}$ & - & - & $0.21 * * *$ & $0.18 * * *$ \\
\hline$F$ & $4.66 * * *$ & $7.16^{* * *}$ & $7.35^{* * *}$ & $6.90 * * *$ \\
\hline$R^{2}$ & 0.14 & 0.19 & 0.19 & 0.21 \\
\hline$\Delta R^{2}$ & - & - & - & 0.02 \\
\hline adj. $R^{2}$ & 0.10 & 0.17 & 0.17 & 0.19 \\
\hline
\end{tabular}

showed that multiple alternative generation mediated 42 percent of the direct effect between strategic planning and decision quality. All models were highly significant and explained between 14 and $21 \%$ of the variance. Subjective performance and Size were only significant in Model 1 as a control variable. All other control variables had no significant effect in the respective models. My first hypothesis could thus be supported.

My second hypothesis was tested in the Models 5-7, which are summarized in Table 3. Here, the same mediation analysis described above was conducted to test for the effect of information integration in the relationship between strategic planning and decision quality.

Also in this analysis, all conditions for mediation were fulfilled. Model 5 showed a positive and highly significant relationship between strategic planning and information integration $(b=0.83, p<0.001)$. In addition, Model 6 indicated a highly significant and positive association between information integration and decision quality $(b=0.26, p<0.001)$. Also, the fourth condition was fulfilled, which is shown in Model 7. Here, the results displayed that the effect of strategic planning was no longer significant $(b=0.12$, n.s.), when information integration is included in the analysis. Instead, information integration showed to be positively associated with decision quality ( $b=0.23, p<0.001)$. Combining these results, the analysis showed that information integration explained 61 percent of the direct 
Table 3 Mediation effect of information integration, according to Baron and Kenny (1986)

\begin{tabular}{|c|c|c|c|c|}
\hline Variables & $\begin{array}{l}\text { Model } 1 \\
\text { decision } \\
\text { quality }\end{array}$ & $\begin{array}{l}\text { Model } 5 \\
\text { information } \\
\text { integration }\end{array}$ & $\begin{array}{l}\text { Model } 6 \\
\text { decision } \\
\text { quality }\end{array}$ & $\begin{array}{l}\text { Model } 7 \\
\text { decision } \\
\text { quality }\end{array}$ \\
\hline \multicolumn{5}{|l|}{ Controls } \\
\hline 1. Perceived Uncertainty & -0.00 & 0.06 & -0.01 & -0.02 \\
\hline $\begin{array}{l}\text { 2. Performance } \\
\text { Expectation (Log) }\end{array}$ & 0.02 & -0.26 & 0.08 & 0.08 \\
\hline $\begin{array}{l}\text { 3. Subjective } \\
\text { Performance }\end{array}$ & $0.11 *$ & $0.18 * *$ & 0.06 & 0.07 \\
\hline $\begin{array}{l}\text { 4. Size } \\
\text { (employees) (Log) }\end{array}$ & $-0.10^{*}$ & -0.09 & -0.06 & -0.08 \\
\hline \multicolumn{5}{|l|}{ Main effects } \\
\hline Strategic planning & $0.32 * *$ & $0.83^{* * * *}$ & - & 0.12 \\
\hline Information integration & - & - & $0.26^{* * *}$ & $0.23 * * *$ \\
\hline$F$ & $4.66^{* * *}$ & $10.47 * * *$ & $8.09 * * *$ & $7.02 * * *$ \\
\hline$R^{2}$ & 0.14 & 0.26 & 0.21 & 0.22 \\
\hline$\Delta R^{2}$ & - & - & - & 0.01 \\
\hline adj. $R^{2}$ & 0.10 & 0.23 & 0.19 & 0.19 \\
\hline
\end{tabular}

effect between the two variables. As in the previous mediation, the only control variables that were significant were subjective performance and size (in Model 1) and subjective performance (in Model 5). All other control variables were not significant.

In sum, these analyses find support for both proposed hypotheses. The results suggest that multiple alternative generation as well as information integration are crucial mediators in the relationship between strategic planning and decision quality.

\section{Discussion}

Both empirical and conceptual research analyzing the effect of strategic planning on the outcome of the strategy process in organizations has yielded mixed results so far. Prior research focused on either a strong process or emergent perspective on planning, which inspired an ongoing debate between these two schools of thought (Ansoff 1991; Mintzberg 1991). However, the results presented in this paper suggest that it may be the precise process characteristics rather than the application of one or the other dominant school of thought, which contributes to a positive effect of strategic planning on the outcome of the strategy process. These findings are in line with Grant (2003), who has shown that managers tend to adopt both perspectives in the planning process of organizations based on the planned emergence perspective of strategic planning. They also suggest that a closer analysis of process characteristics can help mitigate the divergent perspectives on strategic planning, which have been predominant in the last decades of research in the field. 
More precisely, these results show that both the generation of multiple alternatives and the integration of information significantly influence the relationship between strategic planning and decision quality. In fact, both characteristics mediate a large part of the direct effect between these two variables. These findings suggest that the process and design of the strategic planning process has a critical influence on the decision quality obtained in the strategy process. These positive mediation effects can be explained by the cognitive conflict and constructive dissent created in the strategy team caused by information integration and alternative generation. The use of these factors can create a broader consideration of different environmental influence factors, which in turn positively affect the quality of the strategic decision at hand.

From a strategic planning perspective, these results advance the discussion on the effect of strategic planning in organizations. They suggest that it may not be the application of strategic planning itself that alters the outcome of the strategy process but rather how this process is designed and which process characteristics are emphasized. This research thus adds to the discussion initiated by Grant (2003) and presents two process characteristic that can help improve the quality of strategic planning independent from following either the design or process perspective in the domain (Ansoff 1991, 1965; Mintzberg 1991). It contributes towards opening the black box of process-related analyses in the domain of strategic planning research.

In addition, the positive mediating effects presented in this paper present initial support for the claim that strategy processes can be improved if they are designed in an effective way. The results thus also inform organizations on how strategic planning processes can be designed to improve strategy process outcomes in corporate practice.

\subsection{Implications for corporate practice}

This paper highlights that strategic planning activities can be beneficial in organizations if they are structured and designed based on specific process dimensions such as their degree of alternative generation and information integration. This finding can inform corporate practice on how the application of strategic planning can be improved and the overall decision quality obtained in the strategy process can be enhanced. More divergent information and the inclusion of different strategic alternatives considered in the strategic planning process can lead to more effective planning based on a better design, which can increase decision quality as well as the overall profitability of the organization (Amason 1996). This insight seems particularly relevant given the high importance of strategic planning processes among top executives (Rigby and Bilodeau 2007).

\subsection{Limitations and future research}

This study has several limitations, which are inherent in the questionnaire-based research design. First, this study relies on a cross-sectional dataset. Thus, concerns regarding the common method bias as well as potential reverse causalities between the constructs could not be completely dismissed. Still, based on the theoretical and 
empirical argumentation developed in this paper, the results provide a good indication for the role of alternative generation and information integration in the relationship between strategic planning and decision quality. However, future research can complement these suggestions by conducting longitudinal or even experimental studies in the domain, which could more clearly indicate the precise causal relationship between the variables studied here.

The second limitation is the relatively low response rate to the questionnaire. Despite the fact that this rate was in line with other top executive surveys in which confidential topics were analyzed in an SME context, additional and potentially larger scale research on the topic would be beneficial to support my findings on the role of process-based dimensions in the strategic planning process.

A further limitation of this paper lies in the operationalization of information integration and multiple alternative generation used in this study that is based on items suggested by Miller et al. (1998). These operationalizations of the respective constructs provide a good initial step for measuring the influence of process-based characteristics in the strategic planning process. However, to even further improve their connection to the theoretical concepts presented in this paper, these measures could be further improved and fine grained in future research in the domain. The items used to measure multiple alternative generation include the development and consideration of different alternatives in the strategic planning process. This could be amended by items including the precise evaluation of these alternatives. Also, information integration could be measured more directly. This operationalization could for example include items focusing on the information integration of specific internal and external groups. Such an in depths measurement of the respective variables may also contribute towards analyzing the precise measures and techniques used in strategic planning and their respective effects in a more holistic way, which can provide promising avenues for future research in the domain.

This potential for future research in the domain can be derived from another interesting finding of this study, which is that certain process dimensions may not be entirely independent from each other. This can be derived from the high correlation between the two mediators information integration and alternative generation. It implies that both processes are conducted in a parallel way in the strategic planning process of organizations. Also, the results suggest that this application of both process dimensions seems to have an advantageous effect as it increases decision quality in the process.

In addition, the correlation between the mediators indicates that some dimensions of the strategy process, like the ones studied in this paper, seem to belong together and are used in a combined way. Other process dimensions, however, may be used in a supporting way to these core dimensions of strategic planning. This indication may provide two additional interesting avenues for future research in strategic planning research. First, this relatedness of strategic planning dimensions can inform the academic discussion on the planned emergence perspective (Andersen 2000; Brown and Eisenhardt 1997, Grant 2003) as the relatedness of the different goals and measures applied in organizations can help us better understand how to form more accurate descriptions and theorizations of strategic planning processes in 
corporate practice. Second, this finding suggests that future research taking a process-based perspective on the strategy process could focus on a deeper and more fine-grained analysis of the precise measures and techniques used in strategic planning and their respective effects. Such research could for example analyze different kinds of information search behavior or study specific tools for creating multiple alternatives. This could inform research and practice alike on which effect specific measures will have and how their effect is interrelated. The research presented in this paper offers a first indication for the importance of such processbased research that should be complemented by additional and more detailed studies in the future.

Still, given these limitations, this paper introduces important additions to the literature on strategic planning, which can inform future research on process-related factors shaping the planning process in organizations. Especially, I encourage more research analyzing specific process characteristics and their effect on the outcome of strategic planning. This could complement existing research in the domain by showing which underlying characteristics drive the effectiveness of these processes. Such research could analyze other process and process characteristics such as the effect of different team members, their advice-seeking behavior or the degree to which different kinds of information are used in strategic planning.

Moreover, the inclusion of additional outcome measures could complement this study by focusing on the performance effects of effectively designed strategic planning processes. Also, future research could study its effect on micro-level outcomes such as cognitive biases and other psychological constructs that allow for a close integration of individual and group judgment (Powell et al. 2011). Another interesting avenue for future research could be the empirical analysis of dissent and cognitive conflict (Amason 1996), which could investigate the theoretical arguments mentioned in this study on a more quantitative basis.

\subsection{Conclusion}

Thus far, the debate on the effects of strategic planning in organizations has yielded mixed results, both empirically and conceptually. This paper suggests that a more process-oriented perspective on the strategic planning process can inform this discussion and may contribute towards overcoming the divide in strategic planning research. Specifically, I show that the degree to which multiple alternatives are developed and information is integrated in the planning process mediates a large proportion of the relationship between strategic planning and decision quality, as an outcome measure of the strategy process. Thus, I highlight that the design of strategic planning processes can improve strategic decisions and support the claim made by prior research that effectively designed planning processes can in fact be beneficial for corporations.

Acknowledgments I thank Torsten Wulf for his helpful comments on earlier versions of this paper. In addition, I would like to thank Editor Thomas Hutzschenreuter and the anonymous reviewer for his insightful and constructive comments during the review process. 
Open Access This article is distributed under the terms of the Creative Commons Attribution License which permits any use, distribution, and reproduction in any medium, provided the original author(s) and the source are credited.

\section{Appendix: Questionnaire and Variable Scales}

Strategic Planning (Boyd and Reuning-Elliott, 1998)

This section examines several common planning activities.

Please indicate the emphasis placed on each activity within your organization:

\begin{tabular}{|lccccc|}
\hline & \multicolumn{3}{c}{ no } & \multicolumn{3}{c|}{ moderate } & very strong \\
Mission statement & emphasi & emphasis & emphasis \\
Trend analysis & $\square$ & $\square$ & $\square$ & $\square$ & $\square$ \\
Competitor analysis & $\square$ & $\square$ & $\square$ & $\square$ & $\square$ \\
Long-term plans & $\square$ & $\square$ & $\square$ & $\square$ & $\square$ \\
Annual goals & $\square$ & $\square$ & $\square$ & $\square$ & $\square$ \\
Short-term action plans & $\square$ & $\square$ & $\square$ & $\square$ & $\square$ \\
Ongoing evaluation & $\square$ & $\square$ & $\square$ & $\square$ & $\square$ \\
\hline
\end{tabular}

Decision Quality (Amason, 1996)

Please look back to the same non-routine decision evaluated in the question on strategic decision comprehensiveness. How do you evaluate the quality of this decision?

\begin{tabular}{|c|c|c|c|c|c|c|c|}
\hline \multirow[b]{2}{*}{ The quality of the decision relative to its original intent was: } & \multicolumn{5}{|l|}{ poor } & \multicolumn{2}{|c|}{ excellent } \\
\hline & $\square$ & 口 & $\square$ & $\square$ & $\square$ & 口 & 口 \\
\hline The quality of the decision given its effect on organizational performance was: & $\square$ & $\square$ & $\square$ & $\square$ & $\square$ & $\square$ & $\square$ \\
\hline The overall quality of the decision was: & $\square$ & $\square$ & 口 & 口 & $\square$ & 口 & 口 \\
\hline
\end{tabular}

Multiple Alternative Generation (Miller, Burke, and Glick, 1998)

Please look back to an important non-routine decision you have recently made in your company.

To what extent did your firm

\begin{tabular}{|c|c|c|c|c|c|c|c|}
\hline \multirow[b]{2}{*}{ Develop many alternative responses? } & \multicolumn{4}{|c|}{ not at all } & \multicolumn{3}{|c|}{ to a great extent } \\
\hline & $\square$ & $\square$ & $\square$ & $\square$ & $\square$ & 口 & $\square$ \\
\hline Consider many diverse criteria for eliminating possible courses of action? & $\square$ & 口 & $\square$ & $\square$ & 口 & $\square$ & $\square$ \\
\hline
\end{tabular}

Information Integration (Miller, Burke, and Glick, 1998)

Please look back to an important non-routine decision you have recently made in your company. To what extent did your firm

\begin{tabular}{|c|c|c|c|c|c|c|c|}
\hline \multirow{2}{*}{ Thoroughly examine multiple explanations for the problem or opportunity? } & \multicolumn{4}{|c|}{ not at all } & \multicolumn{3}{|c|}{ to a great extent } \\
\hline & $\square$ & $\square$ & $\square$ & $\square$ & $\square$ & 口 & $\square$ \\
\hline Conduct multiple examinations of any suggested course of action? & $\square$ & $\square$ & $\square$ & $\square$ & $\square$ & $\square$ & $\square$ \\
\hline Search extensively for possible responses? & $\square$ & $\square$ & 口 & 口 & $\square$ & 口 & $\square$ \\
\hline
\end{tabular}




\section{Perceived Uncertainty (Miller \& Dröge, 1986)}

Please answer the following questions for the industry tht accounts for the largest $\%$ of your sales (in other words, your principle industry). Always answer by crossing the correct box. How rapid and intense is each of the following in your main industry?

Please cross the box in each scale that best approximates the actual conditions in it.

\begin{tabular}{|c|c|c|c|c|c|c|}
\hline $\begin{array}{l}\text { Our firm must rarely change its marketing practices } \\
\text { to keep up woth the market and competitors }\end{array}$ & 口 & 口 & 口 & 口 & $\square$ & $\begin{array}{l}\text { Our firm must change its marketing } \\
\text { practices extremely frequently (e.g. } \\
\text { semiannually) }\end{array}$ \\
\hline $\begin{array}{l}\text { The rate at which products/services are getting } \\
\text { obsolete in the industry us very slow (e.g. basic } \\
\text { metal like copper) }\end{array}$ & 口 & 口 & 口 & 口 & 口 & $\begin{array}{l}\text { The rate of obsolescence is very high } \\
\text { as in some fashion goods }\end{array}$ \\
\hline $\begin{array}{l}\text { Actions of competitors are quite easy to predict (as } \\
\text { in some primary industries) }\end{array}$ & 口 & 口 & 口 & $\square$ & 口 & $\begin{array}{l}\text { Actions of competitors are } \\
\text { unpredictable }\end{array}$ \\
\hline $\begin{array}{l}\text { Demand and consumer tastes are fairly easy to } \\
\text { forecast }\end{array}$ & 口 & 口 & 口 & 口 & $\square$ & $\begin{array}{l}\text { Demand and tastes are almost } \\
\text { unpredictable (e.g. high fashion goods) }\end{array}$ \\
\hline $\begin{array}{l}\text { The production/service technology is not subject to } \\
\text { very much change and is wells established (e.g. in } \\
\text { steel production) }\end{array}$ & 口 & 口 & 口 & 口 & 口 & $\begin{array}{l}\text { The modes of production/service } \\
\text { change often and in a major way (e.g. } \\
\text { advanced electronic compontents) }\end{array}$ \\
\hline
\end{tabular}

Performance Expectation (Hart \& Banbury, 1994)

Please evaluate your average financial performance in the last five years.

Please evaluate your average financial performance in the last five years.
\begin{tabular}{|lccccccccc|}
\hline \multicolumn{8}{c}{ significantly } & worse & \multicolumn{3}{c|}{ about the same } & \multicolumn{3}{c|}{ significantly better } \\
Relative to your biggest competitor & $\square$ & $\square$ & $\square$ & $\square$ & $\square$ & $\square$ & $\square$ & $\square$ & $\square$ \\
Relative to your most important industry & $\square$ & $\square$ & $\square$ & $\square$ & $\square$ & $\square$ & $\square$ & $\square$ & $\square$ \\
Relative to your plan & $\square$ & $\square$ & $\square$ & $\square$ & $\square$ & $\square$ & $\square$ & $\square$ & $\square$ \\
\hline
\end{tabular}

Subjective Performance (Hart \& Banbury, 1994)

Please evaluate your average performance in the last five years compared to your biggest competitor.

\begin{tabular}{|lccccccccc|}
\hline & significantly & worse & about & some same & \multicolumn{3}{c|}{ significantly better } \\
Sales growth & $\square$ & $\square$ & $\square$ & $\square$ & $\square$ & $\square$ & $\square$ & $\square$ & $\square$ \\
Market share growth & $\square$ & $\square$ & $\square$ & $\square$ & $\square$ & $\square$ & $\square$ & $\square$ & $\square$ \\
Employee growth & $\square$ & $\square$ & $\square$ & $\square$ & $\square$ & $\square$ & $\square$ & $\square$ & $\square$ \\
\hline
\end{tabular}

\section{References}

Ackelsberg, Robert, and Peter Arlow. 1985. Small businesses do plan and it pays off. Long Range Planning 18(5): 61-67.

Agle, Bradley R., Ronald K. Mitchell, and Jeffrey A. Sonnenfeld. 1999. Who matters to CEOs?An investigation of stakeholder attributes and salience, corporate performance, and CEO values. Academy of Management Journal 42(5): 507-525.

Amason, Allen C. 1996. Distinguishing the effects of functional and dysfunctional conflict on strategic decision making: resolving a aaradox for top management teams. Academy of Management Journal 39(1): 123-148.

Andersen, Torben Juul. 2000. Strategic planning, autonomous actions and corporate performance. Long Range Planning 33(2): 184-200.

Ansoff, H.Igor. 1991. Critique of Henry Mintzberg's 'The design school: reconsidering the basic premises of strategic management'. Strategic Management Journal 12(6): 449-461.

Ansoff, Igor. 1965. Corporate strategy. New York: McGraw-Hill.

Armstrong, J.Scott. 1982. The value of formal planning for strategic decisions: review of empirical research. Strategic Management Journal 3(3): 197-211. 
Atuahene-Gima, Kwaku, and Haiyang Li. 2004. Strategic decision comprehensiveness and new product development outcomes in new technology ventures. Academy of Management Journal 47(4): 583-597.

Baron, R.M., and D.A. Kenny. 1986. The moderator-mediator variable distinction in social psychology research: conceptual, strategic, and statistical considerations. Journal of Personality and Social Psychology 51(6): 1173-1182.

Bonaccio, Silvia, and Reeshad S. Dalal. 2006. Advice taking and decision-making: an integrative literature review, and implications for the organizational sciences. Organizational Behavior and Human Decision Processes 101(2): 127-151.

Boyd, Brian K., and Elke Reuning-Elliott. 1998. A measurement model of strategic planning. Strategic Management Journal 19(2): 181-192.

Bradfield, Ronald M. 2008. Cognitive barriers in the scenario development process. Advances in Developing Human Resources 10(2): 198-215.

Breene, R.Timothy S., Paul F. Nunes, and Walter E. Shill. 2007. The chief strategy officer. Harvard Business Review 85(10): 84.

Brews, Peter, and Devavrat Purohit. 2007. Strategic planning in unstable environments. Long Range Planning 40(1): 64-83.

Brown, Shona L., and Kathleen M. Eisenhardt. 1997. The art of continuous change: linking complexity theory and time-paced evolution in relentlessly shifting organizations. Administrative Science Quarterly 42(1): 1-34.

Capon, Noel, and Peter Palij. 1994. Strategic marketing forecasting, market segment selection and firm performance. International Journal of Forecasting 10(2): 339-352.

Churchill, G.A. 1991. Marketing research: Methodological foundations. Chicago: Dryden.

Cruz, Cristina C., Luis R. Gómez-Mejia, and Manuel Becerra. 2010. Perceptions of benevolence and the design of agency contracts: CEO-TMT relationships in family firms. Academy of Management Journal 53(1): 69-89.

Dean Jr, James W., and Mark P. Sharfman. 1996. Does decision process matter?A study of strategic decision-making effectiveness. Academy of Management Journal 39(2): 368-396.

Dean, James W., and Mark P. Sharfman. 1993. The relationship between procedural rationality and political behavior in strategic decision making. Decision Sciences 24(6): 1069-1083.

Delmar, Frederic, and Scott Shane. 2003. Does business planning facilitate the development of new ventures? Strategic Management Journal 24(12): 1165-1185.

Dillman, Don A. 1978. Mail and telephone surveys: The total design method. New York: Wiley.

Dillman, Don A. 1991. The design and administration of mail surveys. Annual Review of Sociology 17(1): 225-249.

Dillman, Don A., Michael D. Sinclair, and Jon R. Clark. 1993. Effects of questionnaire length, respondent-friendly design and a difficult question on response rates for occupant-addressed census mail surveys. Public Opinion Quarterly 57(3): 289-304.

Dooley, Robert S., and Gerald E. Fryxell. 1999. Attaining decision quality and commitment from dissent: the moderating effects of loyalty and competence in strategic decision-making teams. Academy of Management Journal 42(4): 389-402.

Eisenhardt, Kathleen M., and Donald N. Sull. 2001. Strategy as simple rules. Harvard Business Review 79(1): 107-116.

Forbes, Daniel P. 2007. Reconsidering the strategic implications of decision comprehensiveness. Academy of Management Review 32(2): 361-376.

Fredrickson, James W. 1984. The comprehensiveness of strategic decisions processes: extension, observations, future directions. Academy of Management Journal 27(3): 445-466.

Fredrickson, James W., and Terence R. Mitchell. 1984. Strategic decision processes: comprehensiveness and performance in an industry with an unstable environment. Academy of Management Journal 27(2): 399-423.

Grant, Robert M. 2003. Strategic planning in a turbulent environment: evidence from the oil majors. Strategic Management Journal 24(6): 491-517.

Hart, Stuart, and Catherine Banbury. 1994. How strategy-making processes can make a difference. Strategic Management Journal 15(4): 251-269.

Hart, Stuart L. 1992. An integrative framework for strategy-making processes. Academy of Management Review 17(2): 327-351. 
Hitt, Michael A., and Beverly B. Tyler. 1991. Strategic decision models: integrating different perspectives. Strategic Management Journal 12(5): 327-351.

Hodgkinson, Gerard P., Nicola J. Bown, A. John Maule, Keith W. Glaister, and Alan D. Pearman. 1999. Breaking the frame: an analysis of strategic cognition and decision making under uncertainty. Strategic Management Journal 20(10): 977-985.

Hutzschenreuter, Thomas, and Ingo Kleindienst. 2006. Strategy-process research: what have we learned and what is still to be explored. Journal of Management 32(5): 673-720.

Keren, Gideon, and Wändi Bruine de Bruin. 2003. On the assessment of decision quality: considerations regarding utility, conflict and accountability. New York: Wiley.

Korsgaard, M.Audrey, David M. Schweiger, and Harry J. Sapienza. 1995. Building commitment, attachment, and trust in strategic decision-making teams: the role of procedural justice. Academy of Management Journal 38(1): 60-84.

Meissner, Philip, and Torsten Wulf. 2013. Cognitive benefits of scenario planning: its impact on biases and decision quality. Technological Forecasting and Social Change 80(4): 801-814.

Miller, C.Chet. 2008. Decisional comprehensiveness and firm performance: towards a more complete understanding. Journal of Behavioral Decision Making 21(5): 598-620.

Miller, C.Chet, Linda M. Burke, and William H. Glick. 1998. Cognitive diversity among upperechelon executives: implications for strategic decision processes. Strategic Management Journal 19(1): 39 .

Miller, C.Chet, and Laura B. Cardinal. 1994. Strategic planning and firm performance: a synthesis of more than two decades of research. Academy of Management Journal 37(6): 1649-1665.

Miller, Danny, and Cornelia Dröge. 1986. Psychological and traditional determinants of structure. Administrative Science Quarterly 31(4): 539-560.

Mintzberg, Henry. 1991. Learning 1, planning 0 reply to Igor Ansoff. Strategic Management Journal 12(6): 463-466.

Mintzberg, Henry. 1994. The fall and rise of strategic planning. Harvard Business Review 72(1): 107-114.

Olson, Bradley J., Satyanarayana Parayitam, and Yongjian Bao. 2007. Strategic decision making: the effects of cognitive diversity, conflict, and trust on decision outcomes. Journal of Management 33(2): 196-222.

Pearce, John A., Elizabeth B. Freeman, and Richard B. Robinson Jr. 1987. The tenuous link between formal strategic planning and financial performance. Academy of Management Review 12(4): 658-675.

Podsakoff, Philip M., William D. Todor, Richard A. Grover, and Vandra L. Huber. 1984. Situational moderators of leader reward and punishment behaviors: fact or fiction? Organizational Behavior and Human Performance 34(1): 21-63.

Powell, Thomas C., Dan Lovallo, and Craig R. Fox. 2011. Behavioral strategy. Strategic Management Journal 32(13): 1369-1386.

Rigby, D., and B. Bilodeau. 2007. Bain's global 2007 management tools and trends survey. Strategy \& Leadership 35(5): 9-16.

Schoemaker, Paul J.H. 1993. Multiple scenario development: its conceptual and behavioral foundation. Strategic Management Journal 14(3): 193-213.

Schotter, Andrew. 2003. Decision making with naive advice. The American Economic Review 93(2): 196-201.

Schweiger, David M., William R. Sandberg, and Paula L. Rechner. 1989. Experiential effects of dialectical inquiry, devil's advocacy, and consensus approaches to strategic decision making. Academy of Management Journal 32(4): 745-772.

Schwenk, Charles R. 1988. The cognitive perspective on strategic decision making. Journal of Management Studies 25(1): 41-55.

Shrader, Charles B., Lew Taylor, and Dan R. Dalton. 1984. Strategic planning and organizational performance: a critical appraisal. Journal of Management 10(2): 149-171.

Venkatraman, N., and Vasudevan Ramanujam. 1987. Measurement of business economic performance: an examination of method convergence. Journal of Management 13(1): 109.

Wang, Lihua, and Edward J. Zajac. 2007. Alliance or acquisition?A dyadic perspective on interfirm resource combinations. Strategic Management Journal 28(13): 1291-1317.

Wiltbank, Robert, Nicholas Dew, Stuart Read, and Saras D. Sarasvathy. 2006. What to do next? The case for non-predictive strategy. Strategic Management Journal 27(10): 981-998. 
Zellweger, T.M., F.W. Kellermanns, J.J. Chrisman, and J.H. Chua. 2011. Family control and family firm valuation by family CEOs: the importance of intentions for transgenerational control. Organization Science 23(3): 851-868. 